\title{
ASO Author Reflections: Optimal Management of Anal Adenocarcinoma: Clues from a Large, National Database
}

\author{
Gary D. Lewis, $\mathrm{MD}^{1,2}$, and Bin S. Teh, $\mathrm{MD}^{2}$ \\ ${ }^{1}$ Department of Radiation Oncology, The University of Texas Medical Branch at Galveston, Galveston, TX \\ ${ }^{2}$ Department of Radiation Oncology, Houston Methodist Hospital, Cancer Center and Research Institute, Weil Cornell \\ Medical College, Houston, TX
}

\section{PAST}

Adenocarcinoma of the anus is a rare subtype of anal cancer and is thought to represent between 5 and $10 \%$ of all anal cancer cases. ${ }^{1}$ Previous studies have reported that anal adenocarcinoma (AA) carries a worse prognosis when compared with anal squamous cell carcinoma (AS). ${ }^{1,2}$ However, due to the rarity of this disease, there are currently no evidence-based treatment guidelines. AS is treated with definitive chemoradiation (CRT). In contrast, AA has typically been treated similarly to a low-lying rectal adenocarcinoma, i.e. trimodality therapy with neoadjuvant CRT followed by abdominoperineal resection (APR). Unfortunately, the data on this treatment strategy are limited to retrospective institutional reviews.

\section{PRESENT}

The National Cancer Data Base (NCDB) was queried (2004-2015) for patients with $\mathrm{AA}^{3}{ }^{3}$ and was used to collect a large amount of patients to adequately determine the role of trimodality treatment versus CRT alone for this patient population. Data on AS patients were also collected to serve as a comparison population. Median overall survival (OS) was 72.5 and 143.8 months $(p<0.001)$ for AA and

ASO Author Reflections is a brief invited commentary on the article "Survival Outcomes and Patterns of Management for Anal Adenocarcinoma", Ann Surg Oncol. 2019;26:1351-1357.

(C) Society of Surgical Oncology 2019

First Received: 10 May 2019;

Published Online: 29 May 2019

B. S. Teh, MD

e-mail: bteh@houstonmethodist.org
AS patients, respectively. Survival was higher for AA patients undergoing APR within 6 months of CRT (88.3 vs. 58.1 months, $p<0.001$ ) compared with AA patients who had an APR 6 months after CRT. On multivariable analysis, factors associated with worse survival included adenocarcinoma subtype, age $\geq 55$ years, male sex, $T$ stage $\geq 3$, comorbidity score $\geq 1$, lower income, and treatment at a non-academic institution.

\section{FUTURE}

Based on our results, ${ }^{3}$ trimodality treatment is associated with improved OS for these patients. Due to the rarity of this histology, prospective clinical trials are unlikely to accrue enough patients to confirm this benefit. As a result, given the large numbers of patients included, this data may serve as the best resource for providers encountering this rare disease type.

DISCLOSURES Gary D. Lewis and Bin S. Teh have no conflicts of interest to disclose.

\section{REFERENCES}

1. Franklin RA, Giri S, Valasareddy P, Lands LT, Martin MG. Comparative survival of patients with anal adenocarcinoma, squamous cell carcinoma of the anus, and rectal adenocarcinoma. Clin Colorectal Cancer. 2016;15(1):47-53.

2. Anwar S, Welbourn H, Hill J, Sebag-Montefiore D. Adenocarcinoma of the anal canal: a systematic review. Colorectal Dis. 2013;15(12):1481-1488.

3. Lewis GD, Haque W, Butler EB, et al. Survival outcomes and patterns of management for anal adenocarcinoma. Ann Surg Oncol. 2019;26:1351-1357.

Publisher's Note Springer Nature remains neutral with regard to jurisdictional claims in published maps and institutional affiliations. 